Policy Research Working Paper 4512

\title{
Does Participation in Productive Associations Signal Trust and Creditworthiness?
}

Evidence for Nicaragua

Diego F. Angel-Urdinola

Ezequiel Molina

The World Bank

Latin America and the Caribbean Region

Poverty and Gender Groups

February 2008 
Policy Research Working Paper 4512 -

\begin{abstract}
This article studies the extent to which participation in productive associations in Nicaragua contributes to increase individuals' access to social programs and credit services. By participating in productive associations, individuals give a good signal to firms and are rewarded with better transactions and more access to the services they provide, ceteris paribus. Estimates using 2005 data indicate that households that participate in productive
\end{abstract}

associations display higher access to credit and to social programs that promote investment. Additionally, participation in productive associations is weakly associated to more favorable credit outcomes among those households that receive loans, such as lower interest rates and a lower probability of wanting more credit than what was accessible to them.

This paper - a product of LCRPP; Poverty and Gender Groups for Latin America and the Caribbean — is part of a larger effort in the department to enhance understanding on poverty and productivity issues in Nicaragua. Policy Research Working Papers are also posted on the Web at http://econ.worldbank.org. The author may be contacted atdangelurdinola@ worldbank.org.

The Policy Research Working Paper Series disseminates the findings of work in progress to encourage the exchange of ideas about development issues. An objective of the series is to get the findings out quickly, even if the presentations are less than fully polished. The papers carry the names of the authors and should be cited accordingly. The findings, interpretations, and conclusions expressed in this paper are entirely those of the authors. They do not necessarily represent the views of the International Bank for Reconstruction and Development/World Bank and its affliated organizations, or those of the Executive Directors of the World Bank or the governments they represent. 


\title{
Does Participation in Productive Associations Signal Trust and Creditworthiness? Evidence for Nicaragua
}

\author{
$\underline{\text { World Bank }}$
}

Diego F. Angel-Urdinola and Ezequiel Molina*

Key Words: Participation (membership), associations (networks), asymmetry of information, signaling, trustworthiness, social programs, credit.

\footnotetext{
* The World Bank. 1818 H St, NW, Washington, DC 20433, USA.

The views expressed here are those of the authors and need not reflect those of the World Bank, its Executive Directors or the countries they represent. Comments from Florencia Castro-Leal and David Gould are gratefully acknowledged.
} 


\section{Introduction}

This article studies the extent to which participation in productive associations in Nicaragua (i.e. credit unions, professional associations, and local committees) contributes to increase individuals' access to credit and to social programs that promote investment.

Access to networks and associations has become a mechanism for households to promote social participation, empowerment, and better access to services (World Bank, 2007). Participation in associations is important to access markets and inputs (e.g. producer associations); to protect individuals against other institutions (e.g. unions and consumer associations); to gain political power (community committees); and to access goods, programs, or services (e.g. professional associations). For instance, according to World Bank (2007), participation in productive organizations in Nicaragua increases the probability that households benefit from social programs (utility programs, titling programs, agriculture programs, and health and education programs) by 15 to 16 percent.

The government of Nicaragua largely promotes the existence of associations as providers of goods and services, especially in areas where the presence of the state remains weak. Indeed, producer associations in Nicaragua are thoroughly protected under the Municipality Law (Law 45) and the Social Participation Law (Law 475) of 2003. Lack of institutional quality calls for alternative ways to cope with resource allocations and other functions high-quality institutions generally perform. Governance indicators for year 2007 (see Kaufmann el at 2007) indicate that institutions in Nicaragua remain weak, particularly in areas concerning government effectiveness and rule of law. Nicaragua's institutional efficiency ranks below the world's twentieth percentile. All these facts make Nicaragua an interesting study-case for identifying the role of associations as alternative mechanism to access services, such as social programs and credit.

Associations are broadly defined as a group of people who enter into an agreement to reach an end. The concept of association is usually related in the literature with the concept of social capital, defined as features of social life (networks, norms and trust) that enable participants to act together more effectively to pursue shared objectives (Putnam, 1995b). Associations usually solve a collective action problem and could act as vehicles for gaining trust (Wollebaek and Selle, 2002; Putnam, 1993, 1995a, 1995b, 2000). By gaining trust, firms may be more willing to provide individuals who belong to an association with services and programs (such as micro-credits and other programs targeted to the "working" poor) than if otherwise, especially in environments characterized by asymmetric information (Stiglitz and Weiss, 1981).

Our hypothesis is that by participating in associations, individuals give a "good signal" to public and private firms and are rewarded with better transactions and more access to the services they provide, ceteris paribus. This can be true to the extent that associations are somehow exclusive and costly. Some professional associations call for specialized experience, skill requirements, and may involve direct and indirect costs (such as membership fees and volunteer work). As such, not everybody may be able to afford or to qualify to participate in these associations. Being part of an association instills in their members habits of cooperation, solidarity, and public-spiritedness that could make participants more trustworthy (Putnam, 1993). 
In the context of this article, and without loss of generality, private firms are lenders (looking for creditors) and public firms are welfare-offices (seeking beneficiaries for their programs). For lenders, loan decisions are usually complex in environments where asymmetric information abounds (Weiss and Stiglitz, 1981). Lenders, besides looking at observable characteristics of potential creditors, would also like to know if they have not only the ability, but also the intention of repaying their loan (i.e. they would like to know their 'trustworthiness' as potential clients).

Signals of 'trustworthiness' are also valuable in the public sector. For instance, in order to implement social assistance programs to promote investment among the poor (such as housing programs, programs to provide farmers with improved seeds, or conditional cash transfers for families who send their children to school), public entities need to identify beneficiaries who will make the right use of public funds, who will honor the conditions set by the program, and who will make good use of the assets provided by the program.

Our estimates indicate that households that participate in productive associations in Nicaragua (defined as those who seek tangible benefits for their members and their communities; such as professional associations, local committees, and credit unions) display higher access to credit and to social programs that promote investment, such as housing and agricultural programs. Using quasi-randomized experimental techniques, we find that household participation in productive associations increases the probability of having benefited from agricultural and housing programs by 2 to $8 \%$. Furthermore, participation in productive associations (excluding credit unions) increases the probability of having received a loan by 6 to $10 \%$. Additionally, participation in productive associations is weakly linked to more favorable credit outcomes among those households who receive loans. Households who participate in productive associations obtain 1 to 1.5\% lower monthly interest rates on their loans (or 12 to 18\% lower interest rates per year) and display a 4 to $9 \%$ lower probability of wanting more credit, which is a proxy for whether or not households with access to loans were able to satisfy their credit needs.

The paper is organized as follows: section 2 discusses a simple signaling model that allows for the possibility that individuals enter associations to distinguish themselves as being trustworthy under asymmetric information. Section 3 describes the data and the empirical approach to test the main hypothesis. Section 4 summarizes the main results of the empirical experiments. A brief conclusion follows in section 5.

\section{An Illustrative Model}

This section presents a simple model that illustrates how participating in an association may be able to signal trustworthiness of individuals and thereby enhance their access and returns to investments offered by firms. The basic idea of the model is that belonging to an association gives a "good" signal to firms ${ }^{1}$. Individuals (or households) who become members of an association pay a cost (i.e. a member's fee, time, volunteer work, etc.) to become a member of the association. The expected return for this investment is to achieve a signal of trustworthiness visible to firms that will enhance the

\footnotetext{
${ }^{1}$ We follow Spence $(1973,1974)$ approach to model signaling.
} 
return of the assets they provide. We assume that "trustworthy" signals are visible to firms.

Suppose for simplicity that there are two types of individuals, high trustworthy $\left(\theta_{h}\right)$ and low trustworthy $\left(\theta_{l}\right)$. The individuals know if they are trustworthy or not, but firms do not observe this directly. The fraction of high trustworthy individuals in the population is $\lambda$. Once a service or program is given to an individual (i.e. an investment), it achieves a return according to the trustworthiness of individuals. High trustworthy individuals achieve a return, $r_{h}$, and low trustworthy individuals achieve a return, $r_{l}$.

In addition, individuals can send a signal to firms by participating in an association. The cost of participating in an association is different for different types of individuals. The crucial assumption is that $c_{l}>c_{h}$, that is, being part of an association is more costly for low trustworthy individuals. The rationale for this assumption is that for low trustworthy individuals, there is a higher cost of mingling and participating in associations, of taking part in the association's activities, and of strengthening relationships with citizens in the community. Furthermore, being part of these associations may come with some responsibilities, fees, requirements, and rules of conduct that low trustworthy individuals may not be willing to abide by. This assumption is usually known as the "single-crossing" assumption: whereby the indifference curves of high and low trustworthy types intersect only once in the signal space. We also assume for simplicity that there are no principal-agent problems within associations, that the government acts as a benevolent monarch, and that there are a large number of riskneutral firms.

Once individuals decide to be or not to be part of an association, they receive a return based on their expected trustworthiness. This is a game of incomplete information where the informed party (i.e. individuals) moves first.

Let $\Gamma$ denote an indicator function of whether a member is part of an association (denoted by $a$ ). Firms choose to give rewards to individuals conditional on participating on an association, denoted by:

$$
\Gamma(a=1)=r_{h}>\Gamma(a=0)=r_{l},
$$

Note that these rewards are conditioned on being part of a productive association and not directly on trustworthiness, since trustworthiness is not observable by the firms. Suppose further that,

$$
r_{h}-c_{h}>r_{l}>r_{h}-c_{l}
$$

Equation (2) holds partly because $c_{h}<c_{l}$. This assumption, albeit simple, is not innocuous as it allows for the signal to solve the problem of asymmetry of information between the parties. The assumption assures that the returns of the signal for $\theta_{h}\left(\theta_{l}\right)$ individuals are positive (negative). This occurs because the cost for low trustworthy types to send the signal is so expensive that it washes away any potential benefit. If the assumption does not hold and either $r_{l}<r_{h}-c_{l}$ or $r_{h}-c_{h}<r_{l}$, the signal would not be useful in order to solve the asymmetry of information.

Let now check that we are on a separating equilibrium where no deviation is a best response. High trustworthy individuals may decide not participate in an association and get $\Gamma(a=0)=r_{l}$ or to participate and get $\Gamma(a=1)-c_{h}=r_{h}-c_{h}$. However, they will always decide to participate given the assumptions highlighted in (2). Similarly, suppose 
that a low trustworthy individual decides to participate in an association and get $\Gamma(a=1)=r_{h}-c_{l}$. This decision is not in his best interest given the assumptions in (2). Therefore, low trustworthy individuals decide not to participate in associations while high trustworthy individuals decide to do so. Notice that under perfect information (i.e. the individual's type is public knowledge) there would not be individuals willing to pay the cost to participate in an association and associations would not exist ${ }^{2}$.

\section{Figure 1: Separating Equilibria}

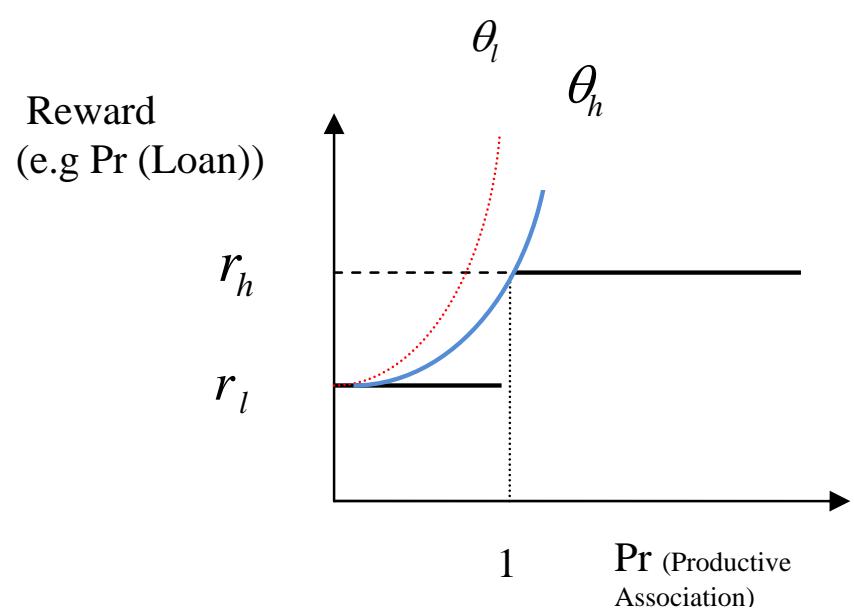

Nevertheless, a separating equilibrium is not the only possible one. A pooling equilibrium, where both types choose not to send the signal could also arise. Consider the following reward structure:

$$
\Gamma(a=1)=\Gamma(a=0)=(1-\lambda) r_{l}+\lambda r_{h},
$$

where

$$
r_{h}-c_{h}>(1-\lambda) r_{l}+\lambda r_{h} \text { and } r_{l}>r_{h}-c_{l} .
$$

Under this set of conditions, no individual has any incentive to participate in an association because it is costly and brings no reward. Firms do not believe that members of associations are different regarding trustworthiness from non-members. ${ }^{3}$

A simple extension that could be added to the simple model presented above is to address what would happen if the problem of asymmetry of information were multidimensional (Streb, 2006). Suppose that individuals not only differ in their trustworthiness but also in their taste for joining an association. This means, that there are people who are gregarious by nature and like to be part of an association. These idiosyncratic factors affect the cost of being part of an association. Of course, this characteristic may introduce noise into the signal, because it does not tell anything about the trustworthiness of individuals. Therefore, there is a risk for the signal to be less

\footnotetext{
${ }^{2}$ This is an extreme result, due to the assumption that being member of an association has no other value but to signal trustworthiness. We address this issue when we consider the case of multidimensional asymmetry of information.

${ }^{3}$ The literature on game theory is continuously evolving. Many refinements of equilibriums (see Cho and Kreps, 1987) could break the pooling equilibrium and bring a separating one where the signal is value by the firms.
} 
informative. Assume that this "taste for being part of an association (gregariousness)" can be high $\left(\xi_{h}\right)$ or low $\left(\xi_{l}\right)$. Now we need a modified single-crossing condition in order to guarantee the separating equilibrium.

$$
r_{h}-c\left(\theta_{h}, \xi_{h}\right)>r_{h}-c\left(\theta_{h}, \xi_{l}\right)>r_{l}>r_{h}-c\left(\theta_{l}, \xi_{h}\right)
$$

If this condition holds, it is easy to check that we are on a separating equilibrium where high trustworthy individuals will join an association and low trustworthy individuals will not ${ }^{4}$.

\section{Figure 2: Separating Equilibria under Two-dimensional Asymmetry of Information}

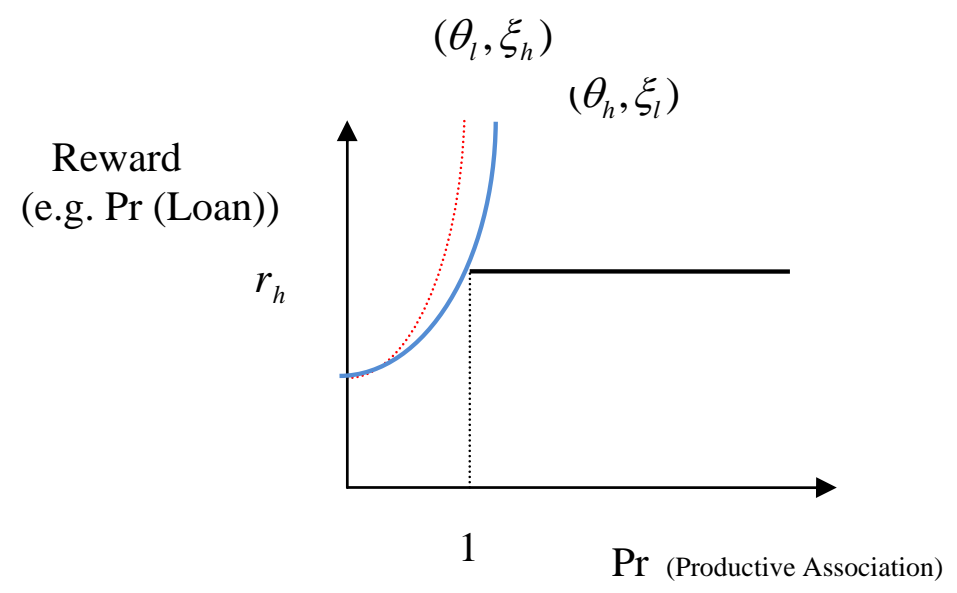

There are many more extensions that could be added to the simple model presented here. For example, we could study what would happen if the government is not a benevolent monarch and uses social plans for its own agenda, or if firms have market power or if being part of an association not only signals but actually increases the trustworthiness of individuals. In this last case, the results of the extension would be analogous to those compiled by the literature of human capital accumulation, whereby education not only a signals but also increases ability. However, we hope to have been able to illustrate a simple point: that under imperfect information from the side of the firms, participation in productive associations may increase the returns obtained by individual under certain conditions.

\section{Empirical Illustration}

The main empirical question in this article consists in testing whether participating in productive associations in Nicaragua affects credit outcomes (such as the probability of getting a loan and the interest rate on the loan) and the probability of benefiting from social assistance programs that promote investment among the poor. Data

\footnotetext{
${ }^{4}$ We will deal with this issue in the empirical section below using a dummy variable that indicates if members of the household participate in associations that are not productive and barely have any cost. These will allow us to control for the fact that there may be some individuals that have an innate taste for being part of an association.
} 
come from the 2005 Encuesta Nacional de Hogares sobre Medicion de Vida (EMNV) developed by the Nicaraguan National Institute of Statistics (INEC). The Survey is stratified, nationally representative, and collects information on general attributes of the entire population. The sample includes 6,861 observations representative of a population of close to 1 million households. The data provide information about participation of individuals in the following associations; i) local committees: group of individuals in a neighborhood (or village) that advocate to local government in order to attend the concerns and needs of the community (such as improving public services or monitoring spending); ii) professional associations: group of individuals that unite to promote common interests to their profession or sector of employment; iii) credit unions: institutions that provide financial services to its members/shareholders; and iv) other type of associations, such as religious groups, fraternities, and clubs. In this paper, we will only analyze the signaling impact of local committees, professional associations, and credit unions as they seek to obtain tangible economic benefits on behalf of their members. For simplicity, we refer to them as productive associations. Of course, when analyzing the influence of productive association in credit outcomes, we exclude credit unions from the analysis since the main purpose of credit unions is to provide credit services to their members. Our objective is then to disentangle the "signaling effect" of associations in outcomes (i.e. access to credit and social programs) from the effect in outcomes that may arise from the nature of the association).

Table 1 provides descriptive statistics on participation in associations. Columns 1 through 5 display the share of households having a head with at least one member participating in productive and non-productive associations. Column 1 indicates that nationally about $6.4 \%$ of all households have at least one member participating in a productive association, the majority of which reside in rural areas $(11 \%$ in rural areas vs. $6 \%$ in urban areas). Columns 2, 3, and 4 display respectively the share of households participating in local committees, credit unions, and professional associations by regions and socio-economic group. Similarly to what occurs nationally, participation in local committees and in professional associations is higher in rural areas and among the nonpoor. Household participation in credit unions is larger in urban areas. Column 5 presents the share of households having at least one member participating in non-productive associations, mainly churches and clubs.

Table 2 provides descriptive statistics on access to social programs and credit. The 2005 EMNV includes a module that gathers information on whether or not households benefited from social programs. Out of a list of 23 programs, we identified 2 social assistance programs that provide free or subsidized assets to promote investment among the poor: agricultural programs and housing programs. Agricultural programs include information on three ongoing programs in Nicaragua: libra por libra, huertos caseros, and the forestation programs. Data do not permit to analyze each program independently. These programs provide households working in agriculture with some type of investment asset; such as improved seeds, plants, and trees. Housing programs provide households with land, labor, and/or materials to build or remodel their dwelling. Columns 1 and 2 in Table 2 display the share of households benefiting from the aforementioned programs. Descriptive statistics indicate that only about 3 (1) percent of all households claim to have benefited from agricultural (housing) programs; most of 
which live in poor-rural regions (mainly Central and Atlantic) and belong to the poorest segments of the population. ${ }^{5}$

Columns 3 and 4 display statistics on access to credit from informal and formal sources. Formal credit is that obtained from private banks, the government/MAGFOR, micro-finance institutions, credit cards, cooperatives, and non conventional banks. Informal credit is that obtained from merchants, informal lenders (known as "usureros"), family, and fiends. Results indicate that the majority of loans in Nicaragua are issued by informal lenders. Approximately 13\% to16\% percent of all households in all socioeconomic groups and strata claim to have received a loan from informal sources. Not surprisingly, access to formal loans is higher in urban areas (12\% vs. $8 \%$ in rural areas) and among the non-poor ( $13 \%$ vs. $6 \%$ among the poor). The analysis that follows analyses credit outcomes from both formal and informal credit sources.

In order to test to whether participation in productive associations signals trustworthiness and therefore may enhance access to credit and access to social programs that promote investment, we rely on matching techniques. Although fully randomized social experiments are considered more appropriate for causal inference (Grossman, 1994; Holland, 1986; and Newman et. al, 1994), non experimental evaluations provide an alternative evaluation method.

Define a vector of outcomes $Y_{j}$ for each values of $M P A_{j}=\{0,1\}$. Let $M P A=1$ denote households with at least one individuals who is are member of productive associations and let $M P A=0$ denote otherwise. The parameter of interest, denoted by $R E W$ (reward), shows the difference between outcomes of interest in the treated state $\left(Y_{1}\right)$ with the outcomes in the control state $\left(Y_{0}\right)$ conditional on receiving treatment:

$$
\begin{aligned}
R E W & =E\left(Y_{1}-Y_{0} \mid M P A=1\right)=E(\Delta Y \mid M P A=1) \\
& =E\left(Y_{1} \mid M P A=1\right)-E\left(Y_{0} \mid M P A=1\right)
\end{aligned}
$$

We are able to observe $E\left(Y_{1} \mid M P A=1\right)$ from the data but not $E\left(Y_{0} \mid M P A=1\right)$, which is the counterfactual of interest. However, we can observe the average outcome in the control state $E\left(Y_{0} \mid M P A=0\right)$, which we can use as an estimate for the counterfactual. The central problem becomes then to obtain a good estimate for the unobservable component. Nevertheless, participants and non-participants are different in many ways, including the effect of the program. Therefore,

$$
E(\triangle Y \mid M P A=1) \neq E\left(Y_{1} \mid M P A=1\right)-E\left(Y_{0} \mid M P A=0\right) .
$$

Propensity score matching provides a way to estimate $E(\Delta Y \mid M P A=1)$ under the assumption that, conditional on observable characteristics $X$, participation is independent of outcomes (e.g. treatment status is random conditional on $X$ ). This property in known as the conditional independence assumption (CIA):

$$
\left(Y_{0}, Y_{1}\right) \perp M P A \mid X
$$

\footnotetext{
${ }^{5}$ We are aware that the size of the housing program is small. However, we decided to include it in the analysis in order to take advantage of all the data at hand.
} 
Using Dehajia and Wahba's (2002) methodology, tests on our data suggest that the CIA property holds. Furthermore, we assume that CIA is not satisfied given observables but would be satisfied if we could observe an additional binary variable (following Ichino et al., 2006). The test allows us to simulate this variable in the data and used it as an additional matching factor. Then a comparison of the estimates obtained with and without matching on this simulated variable tells us to what extent the estimator is robust to this specific source of failure of the CIA.

If the CIA assumption true, then we can estimate $R E W$ as using propensity score matching techniques (Rosembaum and Rubin, 1983) so that:

$$
\begin{aligned}
\operatorname{REW}(X) & =E(\Delta Y \mid M P A=1, P(X)) \\
& =E\left(Y_{1} \mid M P A=1, P(X)\right)-E\left(Y_{0} \mid M P A=0, P(X)\right)
\end{aligned}
$$

Where $P(X)=\operatorname{Pr}(M P A=1 \mid X)$ is the propensity score To estimate (8) we rely on kernel matching (Epanechnikov and Gaussian kernel). Additionally, to check the robustness of our results we use radius matching techniques. We exclude observations with matches outside of the boundaries of the common support (or probability of being treated given that they are not).

\section{4. $\quad$ Results}

Table 3 presents estimates of the likelihood that households participate in productive associations conditional on characteristics such as socio-economic conditions, education/employment of the head, and region using a probit model. These variables are used to control for observable characteristics in the first step of the matching procedure. Results indicate that more educated households are more likely to participate in productive associations. Households having a head who attained primary, secondary, and tertiary education are $4 \%, 5 \%$, and $11 \%$ more likely to participate in productive associations than households having a head with no education. Furthermore, wealthier households are also more likely to participate in productive associations. Households in the top two quintiles are 5\% to 7\% more likely to participate in productive associations as compared to households in the bottom quintiles. Households having a self-employed head as well as those having a head working in agriculture are 3\% more likely to participate in productive associations than households having a head working as wage earners or in non-agriculture-related activities. Households living in the central region are associated with a 4\% higher probability of participating in productive associations vs. those residing in Managua. All this evidence is in accord with the literature showing that the poor and disadvantaged have usually lower rates of participations in community associations, not just in Nicaragua but all over the globe (Almond and Verba, 1965; Schlozman and Brady, 1995; Ayala, 2000; Gugerty and Kremer, 2006).

Note that the estimates of the propensity score include a dummy variable that takes a value of one if a member of the household participates in a non-productive association, such as a sport club or religious association. These associations do not have high participation costs so they do not necessarily serve to signal trustworthiness under 
the framework discussed in section 2. However, participation in non-productive associations is a useful control for the level of gregariousness of the household. ${ }^{6}$

Results of the matching experiments are presented in Table 3. The first set of results examine how household participation in productive association influences the probability that a households benefits from agriculture and housing programs. For these experiments we have 589 observations in the treatment groups (nearly 10 percent of the sample) and with 6,064 in the control groups. All observations are in the region of common support. Estimates indicate that household participation in productive associations increases the probability that households benefits from agricultural programs by 6 to $10 \%$. Results are robust to the choice of matching technique and statistically significant as suggested by the z-statistics presented in Table $4^{7}$, column 5 . Estimates also suggest that participation in productive associations increases the probability that households benefit from housing programs by less than 2 percent. However, this last result is marginally significant and not robust to the choice of matching techniques. Anyhow, the size of the program (i.e. only 1 percent of all households benefit from it) is rather small for conducting this type experiment.

The second set of results examines how household participation in productive associations (excluding credit unions) influences in the probability that households received a loan within a year previous to the survey. The experiment is conducted with 500 observations in the treatment group and with 6,132 in the control group. Estimates indicate that household participation in productive associations increases the probability of having received a loan by 7 to $10 \%$. As in the previous case, results are robust to the choice of matching techniques and statistically significant ${ }^{8}$.

The third set of results examines the average interest paid among households that received a loan. For this experiment we do not have as many degrees of freedom because many households do not report the interest rate linked to their loan and also due to the common support restriction. The experiment is conducted with 40 observations in the treatment group and with 175 in the control group. Results indicate that households that participate in productive associations obtain 1 to $1.5 \%$ lower monthly interest rates on their loans (or $12 \%$ to $18 \%$ lower interest rates per year). This is a very important result and suggests large savings in the cost of money related to participation in productive associations. Nevertheless, these results are not robust to all choices of matching techniques and the number of observations is not enough to have robust estimates.

The last set of results examines how household participation in productive associations influences the probability that households that received a loan claim to want more credit (i.e. this is a proxy of whether or not households with access to loans were able to satisfy their credit needs). For this experiment, we lose degrees of freedom as the sample includes only those households that received a loan and due to the common

\footnotetext{
${ }^{6}$ In this article we analyze two main outcomes associated with participation in productive associations; they are access to credit and participation in social programs. The model presented in Table 2 is the one used to estimate the propensity score used to analyze outcomes on participation in social programs. To analyze credit outcomes, we changed the specification slightly in order to satisfy the balancing property (and excluded credit unions from the analysis). Results are available upon request. We do not present them to avoid duplication since they are very similar.

${ }^{7}$ As we acknowledge the work of Abadie et al (2006) we have checked that results do not differ when not using boostrap estimation. Results are available upon request.

${ }^{8}$ For the Kernel Gaussian the result is not statistically significant at 95\% level of confidence.
} 
support restriction. Note that among those that received a credit, about one-fifth said they wanted more credit. The experiment is conducted with 123 observations in the treatment group and 854 in the control group; all are in the region of common support. Estimates indicate that household participation in productive associations decreases the probability of wanting more credit (among those who received a loan) by 3 to $9 \%$. As in the previous set of results, estimates are significant only at the margin and are not robust to all choices of matching techniques.

In order to assess the robustness of our estimates to the CIA assumption, we rely on including calibrated cofounders to our model following Ichino et al. (2006). The idea of the calibrated cofounders is to analyze the extent to which our propensity score model missed important variables that may explain the latent distribution of household participation in productive associations. This is done by simulating potential cofounders in the data, a calibrated cofounder that has a distribution similar to the empirical distribution of an important binary covariate, in this case, a dummy variable that is equal to one when a household member participates in a non-productive association. By doing so, the simulation reveals the extent to which baseline estimates are robust to deviations from CIA induced by the impossibility of observing factors similar to those used to calibrate the distribution of the cofounder, i.e. being part of a non-productive association.

Results of the robustness checks are presented in Tables 4A and 4B. In regards to our first experiment (i.e. effect of participation on the probability of benefiting from a social program in agriculture), estimates using a calibrated cofounder are very similar to the baseline estimates. This means that even though the calibrated cofounder inflicts a positive effect on the untreated outcome and on the treatment assignment, the effect over the estimate is not strong. So, even if we do not include or cannot observe a variable similar to the calibrated cofounder, baseline estimations would not changed significantly. Altogether, this means that these results are quite robust. In regards to our second experiment (i.e. effect of participation on the probability of obtaining credit), the effect of the calibrated cofounder in the magnitude of the estimate is negligible. We cannot perform cofounder tests in the other experiments (i.e. effect on participation on interest rates and on wanting more credit) due to lack of degrees of freedom (i.e. we run into multi-colinearity problems by adding cofounders to the model).

\section{Conclusions}

Results in this article indicate that no matter the level of income (poverty), geographic location, sex, skills, occupation, etc. household participation in productive associations in Nicaragua contributes to increase household access to credit and to social assistance programs that promote investment. Participation in productive associations is linked (although weakly) to more favorable credit outcomes among those households that receive loans, such as lower interest rates and a lower probability of wanting more credit. The results show the relevance of these associations in providing the community with better outcomes regarding relationships with the public and private sectors. The results also give some theoretical foundations for developing community-based associations such as the Self-employed Women's Association in India, the Orangi Slum Association in Pakistan, and the Iringa Nutrition Association in Tanzania, among others (Mansura and Rao, 2004). 
Our theory is that being part of an association signals a participant's trustworthiness and reliability. A key assumption is that trustworthiness is rewarded by firms with better transactions and more access to the services they provide. Specialized associations that are somehow selective about their members and that involve direct or indirect membership costs may contribute to reduce asymmetry of information and thereby may be beneficial to enhance credit markets. Furthermore, productive associations may help the public sector identify good candidates to benefit from programs that require conditionality and targeting.

Estimates obtained in this article indicate that households that are involved in productive associations in Nicaragua are associated with $6 \%$ to $10 \%$ higher access to credit and to social assistance agricultural programs that promote investments, mainly among the rural poor.

Results presented here focus on the signaling impact of productive associations (i.e. those that are designed to bring tangible benefits to their members) as opposed to that of any other type of association. The logics behind this choice is that productive associations usually entail direct or indirect costs to their members, which is the driving force that contributes to obtain a signal about their trustworthiness. Nevertheless, other non-productive associations, such as some religious groups, may promote values that may enhance the trustworthiness of their members. Testing this hypothesis is an empirical question that may be worth analyzing in future research in this area.

\section{References}

Abadie, A. and Imbens, G. (2006) On the Failure of the Bootstrap for Matching Estimators. NBER Working Paper.

Almond, G. and Verba, S. (1965) The Civic Culture: Political Attitudes and Democracy in Five Nations. Boston: Little and Brown.

Ayala, L. (2000) Trained for Democracy: The Differing Effects of Voluntary and Involuntary Organizations on Political Participation. Political Research Quarterly. 53 (1) March.

Cho, I. and Kreps, D. (1987) Signaling Games and Stable Equilibria, Quarterly Journal of Economics. Vol. 102(2), pp. 179-221.

Dehajia, R. and Wahba, S. (2002). Propensity Score Matching for Non Experimental Causal Studies. Review of Economic and Statistics, Vol. 84: 151-61

Grossman, J. (1994). Evaluating Social Policies: Principles and U.S. Experience. World Bank Research Observer, Vol. 9 (2): 159-80

Gugerty, M. and Kremer, M. (2006) Outside Funding and the Dynamics of Participation in Community Associations. Working Paper. 
Holland, P. (1986). Statistics and Causal Inference. Journal of the American Statistical Association, Vol 81: 945-60

Ichino, A. , Mealli, F. and Nannicini, T. (2006). "From Temporary Help Jobs to Permanent Employment: What Can We Learn from Matching Estimators and their Sensitivity?," IZA Discussion Papers 2149, Institute for the Study of Labor (IZA).

Kaufmann D., Kraay A., and Mastruzzi M. (2007): Governance Matters VI: Governance Indicators for 1996-2006. World Bank. Washington D.C.

Newman, J.; Rawling, L.; and Gertler, P. (1994). Using Randomizes Control Designs in Evaluating Social Sector Programs in Developing Countries. World Bank Research Observer, Vol. 9(2): 181-2001

Rosembaum, P. and Rubin, D. (1983). The Central Role of the Propensity Score in Observational Studies for Causal Effects. Biometrica, Vol. 70:604-20

Spence, M. (1974). Market Signaling: Informational Transfer in Hiring and Related Processes, Cambridge: Harvard University Press.

Spence, M. (1973), Job Market Signaling, Quarterly Journal of Economics, August 1973.

Stiglitz, J. and Weiss, A. (1981) Credit Rationing in Markets with Imperfect Information The American Economic Review, Vol. 71(3): 393-410.

Streb, J. (2006). "Job market signals and signs," CEMA Working Papers 326, Universidad Del CEMA

Putnam, R. D. (1993). Making democracy work: Civic traditions in modern Italy. Princeton, NJ: Princeton University Press.

Putnam, R. D. (1995a). Bowling alone: America's declining social capital. Journal of Democracy, Vol. 1: 65-78.

Putnam, R. D. (1995b). Tuning in, tuning out: The strange disappearance of social capital in America. Political Science and Politics, Vol. 28: 664-683.

Putnam, R. D. (2000). Bowling alone: The collapse and revival of American community. New York: Simon \& Schuster.

Verba, S., Schlozman, K.L. and Brady, H.E. (1995). Voice and Equality: Civic Voluntarism in American Politics. Cambridge, MA: Harvard University Press.

Wollebaek D. and Selle P. (2002) Does Participation in Voluntary Associations Contribute to Social Capital? The Impact of Intensity Scope, and Type Nonprofit and 
Voluntary Sector Quarterly; 31; 32

http://nvs.sagepub.com/cgi/content/abstract/31/1/32

World Bank 2007. Nicaragua Poverty Assessment. Report No. 39736 - NI. Washington D.C. 
Table 1: Descriptive Statistics on Household Participation in associations

\begin{tabular}{|c|c|c|c|c|c|}
\hline & $\begin{array}{c}\text { Any } \\
\text { Productive } \\
\text { Association } \\
\% \\
\%\end{array}$ & $\begin{array}{c}\text { Professional } \\
\text { Associations } \\
\\
\% \\
\end{array}$ & $\begin{array}{c}\text { Credit } \\
\text { Unions } \\
\\
\% \\
\end{array}$ & $\begin{array}{c}\text { Local } \\
\text { Committees } \\
\\
\% \\
\end{array}$ & $\begin{array}{l}\text { Other non- } \\
\text { productive } \\
\text { association } \\
\qquad \%\end{array}$ \\
\hline & \multicolumn{5}{|c|}{ HOUSEHOLD PARTICIPATION } \\
\hline $\begin{array}{l}\text { Total } \\
\text { Area }\end{array}$ & 6.37 & 2.30 & 1.76 & 4.47 & 12.50 \\
\hline Rural & 10.50 & 3.07 & 1.19 & 6.91 & 13.20 \\
\hline Urban & 6.01 & 1.75 & 2.16 & 2.72 & 12.00 \\
\hline \multicolumn{6}{|l|}{ Region } \\
\hline Managua & 7.03 & 1.83 & 2.95 & 2.80 & 16.46 \\
\hline Pacific & 6.69 & 1.85 & 1.38 & 4.21 & 8.08 \\
\hline Central & 9.98 & 3.33 & 1.48 & 5.90 & 12.76 \\
\hline Atlantic & 7.15 & 1.75 & 0.88 & 4.89 & 14.02 \\
\hline \multicolumn{6}{|l|}{ Quintile } \\
\hline Quintile 1 & 6.86 & 2.29 & 0.13 & 4.68 & 10.18 \\
\hline Quintile 3 & 8.35 & 1.77 & 1.58 & 5.35 & 13.41 \\
\hline Quintile 5 & 8.78 & 3.16 & 2.40 & 4.37 & 14.12 \\
\hline \multicolumn{6}{|l|}{ Poverty } \\
\hline Non poor & 8.66 & 2.29 & 0.13 & 4.68 & 13.66 \\
\hline Poor & 6.57 & 1.77 & 1.58 & 5.35 & 10.53 \\
\hline Number of & & 6861 & 6861 & 6861 & \\
\hline Observations & 6861 & & & & 6861 \\
\hline
\end{tabular}

Source: Authors using the 2005 Nicaragua EMNV. 
Table 2: Descriptive Statistics on Household access to credit and social assistance programs

\begin{tabular}{|l|cccc}
\hline & $\begin{array}{c}\text { Benefited from a } \\
\text { Housing program }\end{array}$ & $\begin{array}{c}\text { Benefited from an } \\
\text { Agriculture } \\
\text { program } \\
\%\end{array}$ & $\begin{array}{c}\text { Received a loan } \\
\text { from an formal } \\
\text { creditor } \\
\%\end{array}$ & $\begin{array}{c}\text { Received a loan } \\
\text { from a informal } \\
\text { creditor } \\
\%\end{array}$ \\
\hline $\begin{array}{l}\text { Total } \\
\text { Area }\end{array}$ & 1.07 & 2.63 & 10.42 & 15.04 \\
$\quad$ Rural & 1.52 & 6.03 & 7.82 & 15.5 \\
$\quad$ Urban & 0.74 & 0.19 & 12.28 & 14.71 \\
$\begin{array}{c}\text { Region } \\
\text { Managua }\end{array}$ & 0.20 & 1.37 & 12.79 & 13.31 \\
$\quad$ Pacific & 0.63 & 1.34 & 10.42 & 15 \\
$\quad$ Central & 2.46 & 5.03 & 11.44 & 17.38 \\
Atlantic & 0.40 & 2.20 & 2.95 & 12.8 \\
Quintile & & & & \\
$\quad$ Quintile 1 & 2.04 & 4.80 & 4.11 & 16.25 \\
$\quad$ Quintile 3 & 0.80 & 3.04 & 7.09 & 16.25 \\
$\quad$ Quintile 5 & 0.44 & 1.06 & 15.89 & 12.43 \\
Poverty & & & & \\
$\quad \begin{array}{l}\text { Non poor } \\
\text { Poor }\end{array}$ & 0.79 & 2.03 & 12.96 & 14.59 \\
$\begin{array}{l}\text { Number of } \\
\text { Observations }\end{array}$ & 1.55 & 3.63 & 6.13 & 6861 \\
\hline
\end{tabular}

Source: Authors using the 2005 Nicaragua EMNV. Formal creditors: private banks, government/MAGFOR, micro-finance institutions, credit cards, cooperatives, and Non conventional banks; Informal Creditors: Merchants, informal lenders or "usureros", family, and fiends. Social Programs: utility programs, titling programs, agriculture programs, and health and education programs 
Table 3: Direct estimates of the bias in the dependent Variable due to observable characteristics [Probit regression]

\begin{tabular}{|c|c|c|c|c|}
\hline $\begin{array}{l}\text { Dependent Variable: a member of the household } \\
\text { participates in a productive association }\end{array}$ & $d F / d x$ & Coeff. & $\begin{array}{c}\text { Standard } \\
\text { Error }\end{array}$ & $\begin{array}{c}z- \\
\text { Statistic } \\
\end{array}$ \\
\hline \multicolumn{5}{|l|}{ Characteristics of the household } \\
\hline Log. of Household size & $0.01 * * *$ & $0.27 * * *$ & 0.06 & 0.00 \\
\hline Head is indigenous & -0.02 & -0.12 & 0.10 & 0.22 \\
\hline Household is poor & -0.02 & -0.12 & 0.12 & 0.32 \\
\hline Head is male & 0.01 & 0.12 & 0.09 & 0.15 \\
\hline Age of the head & 0.00 & $-0.01 * * *$ & 0.00 & 0.01 \\
\hline Age of the spouse & $0.0009 * *$ & $0.01^{* *}$ & 0.00 & 0.03 \\
\hline Main way is accessible all the time & $-0.02 * * *$ & $-0.18 * * *$ & 0.06 & 0.00 \\
\hline Head is widowed & $0.06^{* * *}$ & $0.37 * * *$ & 0.10 & 0.00 \\
\hline Head is living in couple & -0.02 & -0.14 & 0.15 & 0.35 \\
\hline Household owns house & 0.01 & $0.20^{* * *}$ & 0.07 & 0.00 \\
\hline H. participates in a non-productive organization & $0.10^{* * *}$ & $0.59 * * *$ & 0.06 & 0.00 \\
\hline \multicolumn{5}{|l|}{ Socio Economic Condition } \\
\hline Quintile 2 & 0.02 & 0.13 & 0.08 & 0.12 \\
\hline Quintile 3 & $0.03^{*}$ & $0.22 *$ & 0.12 & 0.06 \\
\hline Quintile 4 & $0.05^{* *}$ & $0.34 * *$ & 0.14 & 0.02 \\
\hline Quintile 5 & $0.07 * * *$ & $0.49 * * *$ & 0.15 & 0.00 \\
\hline \multicolumn{5}{|l|}{ Age Dummies } \\
\hline Head have $16-23$ years & $-0.06 * * *$ & $-1.02 * * *$ & 0.30 & 0.00 \\
\hline Head have $24-33$ years & $-0.03 * * *$ & $-0.20 * *$ & 0.08 & 0.01 \\
\hline \multicolumn{5}{|l|}{ Occupation of the Head } \\
\hline Head is self-employed & $0.03 * * *$ & $0.22 * * *$ & 0.05 & 0.00 \\
\hline Head works in Commerce & 0.00 & -0.04 & 0.08 & 0.61 \\
\hline Head works in Finance & $0.08^{* * *}$ & $0.45^{* * *}$ & 0.15 & 0.00 \\
\hline Head works for the government & 0.01 & 0.09 & 0.17 & 0.60 \\
\hline Head works in Agriculture or Mining & $0.03^{* * *}$ & $0.25 * * *$ & 0.07 & 0.00 \\
\hline Spouse is professional & 0.03 & 0.23 & 0.22 & 0.31 \\
\hline \multicolumn{5}{|l|}{ Education of the Head } \\
\hline Head finished primary school & $0.04 * * *$ & $0.27 * * *$ & 0.06 & 0.00 \\
\hline Head finished secondary school & $0.05^{* * *}$ & $0.34 * * *$ & 0.09 & 0.00 \\
\hline Head finished technical & $0.11^{* * *}$ & $0.57 * * *$ & 0.14 & 0.00 \\
\hline Head finished tertiary & $0.09 * * *$ & $0.51^{* * *}$ & 0.12 & 0.00 \\
\hline \multicolumn{5}{|l|}{ Regions } \\
\hline Region: Managua & 0.00 & -0.02 & 0.11 & 0.82 \\
\hline Region: Pacific & 0.01 & 0.07 & 0.07 & 0.34 \\
\hline Region: Central & $0.04 * * *$ & $0.30 * * *$ & 0.06 & 0.00 \\
\hline
\end{tabular}

Source: Authors using the 2005 Nicaragua EMNV. Absolute value of $\mathrm{z}$ statistics in brackets. * significant at $10 \%$; ** significant at 5\%; *** significant at $1 \%$. Reference categories: education of the head, no education or preschool; socio-economic group, poorest quintile; geographic location, Atlantic. 
Table 4A: Matching results on Social Assistance [effect of participation in productive association on access to social programs]

\begin{tabular}{|c|c|c|c|c|c|c|c|}
\hline & $\begin{array}{c}N \text { treated } \\
\text { on support }\end{array}$ & $\begin{array}{l}N \text { control } \\
\text { on support }\end{array}$ & ATET & $\begin{array}{l}\text { Boostrap } \\
\text { s.e. }\end{array}$ & $\begin{array}{c}\mathrm{z}- \\
\text { Statistic }\end{array}$ & 95\% Conf. & Interval \\
\hline \multicolumn{8}{|c|}{$\begin{array}{l}\text { Probability of benefiting from a social program in } \\
\text { Agriculture (in \%) }\end{array}$} \\
\hline Kernel Matching (epanechnikov) & 588 & 6,064 & $8.3 \%$ & 0.015 & 5.67 & $5.4 \%$ & $11.1 \%$ \\
\hline Kernel Matching (Gaussian) & 588 & 6,065 & $6.4 \%$ & 0.017 & 3.80 & $3.1 \%$ & $9.7 \%$ \\
\hline Radius Matching & 588 & 6,065 & $9.57 \%$ & 0.011 & 8.99 & $7.5 \%$ & $11.6 \%$ \\
\hline Radius Matching, caliper(0.01) & 588 & 6,064 & $8.2 \%$ & 0.016 & 5.28 & $5.2 \%$ & $11.3 \%$ \\
\hline Radius Matching, caliper(0.05) & 589 & 6,064 & $8.30 \%$ & 0.014 & 5.74 & $5.5 \%$ & $11.1 \%$ \\
\hline Calibrated cofounder ${ }^{*}$ & & & & & - & - & - \\
\hline $\operatorname{Pr} U=1$ if $T=1$ is 0.30 ; if $T=0$ is 0.10 & 589 & 6,065 & $7.7 \%$ & 0.003 & & & \\
\hline \multicolumn{8}{|c|}{ Probability of benefiting from a housing program (in \%) } \\
\hline Kernel Matching (epanechnikov) & 588 & 6,064 & $1.2 \%$ & 0.008 & 1.62 & $-0.3 \%$ & $2.8 \%$ \\
\hline Kernel Matching (Gaussian) & 588 & 6,065 & $0.3 \%$ & 0.011 & 0.31 & $-1.8 \%$ & $2.5 \%$ \\
\hline Radius Matching & 588 & 6,065 & $1.3 \%$ & 0.006 & 2.10 & $0.1 \%$ & $2.6 \%$ \\
\hline Radius Matching, caliper(0.01) & 588 & 6,064 & $1.3 \%$ & 0.007 & 1.84 & $-0.1 \%$ & $2.6 \%$ \\
\hline Radius Matching, caliper(0.05) & 588 & 6,064 & $1.3 \%$ & 0.008 & 1.61 & $-0.2 \%$ & $2.8 \%$ \\
\hline Calibrated cofounder ${ }^{+}$ & & & & & - & - & - \\
\hline $\operatorname{Pr} U=1$ if $T=1$ is 0.30 ; if $T=0$ is 0.10 & 589 & 6,065 & $1.3 \%$ & 0.001 & & & \\
\hline
\end{tabular}

Source: Authors using the 2005 Nicaragua EMNV. The program, previous to perform the sensibility analysis, calculates a baseline estimate. In this case using kernel matching and only observation on the common support the baseline estimate is: ${ }^{*} 8.7$ percent; and ${ }^{+} 1.3$ percent. 
Table 4B: Matching results on Access to Credit [effect of participation in productive association on access to loans]

\begin{tabular}{|c|c|c|c|c|c|c|c|}
\hline & $\begin{array}{c}N \text { treated on } \\
\text { support }\end{array}$ & $\begin{array}{l}N \text { control on } \\
\text { support }\end{array}$ & ATET & $\begin{array}{c}\text { Boostrap } \\
\text { s.e. }\end{array}$ & $\begin{array}{c}\mathrm{Z}- \\
\text { Statistic }\end{array}$ & 95\% Conf. & Interva \\
\hline \multicolumn{8}{|l|}{ Probability of receiving credit } \\
\hline Kernel Matching (epanechnikov) & 499 & 6,132 & $8.0 \%$ & 0.023 & 3.39 & $3.4 \%$ & $12.5 \%$ \\
\hline Kernel Matching (Gaussian) & 499 & 6,132 & $6.8 \%$ & 0.035 & 1.89 & $-0.2 \%$ & $13.9 \%$ \\
\hline Radius Matching & 500 & 6,132 & $9.5 \%$ & 0.017 & 5.39 & $6 \%$ & $13 \%$ \\
\hline Radius Matching, caliper(0.01) & 498 & 6,130 & $7.3 \%$ & 0.024 & 2.98 & $2.5 \%$ & $12 \%$ \\
\hline Radius Matching, caliper(0.05) & 499 & 6,132 & $8.0 \%$ & 0.020 & 3.96 & $4 \%$ & $12 \%$ \\
\hline Calibrated cofounder $^{++}$ & & & & & - & - & - \\
\hline $\operatorname{Pr} U=1$ if $T=1$ is 0.30 ; if $T=0$ is 0.10 & 500 & 6132 & $7.6 \%$ & 0.003 & & & \\
\hline \multicolumn{8}{|l|}{ Less interest rate paid (monthly) in points } \\
\hline Kernel Matching (epanechnikov) & 40 & 175 & -1.48 & 0.698 & -2.12 & -2.9 & -0.1 \\
\hline Kernel Matching (Gaussian) & 40 & 175 & -0.64 & 1.580 & -0.41 & -3.8 & 2.5 \\
\hline Radius Matching & 40 & 175 & -1.34 & 0.526 & -2.55 & -2.4 & -0.3 \\
\hline Radius Matching, caliper(0.01) & 40 & 175 & -0.66 & 1.000 & -0.66 & -2.6 & 1.3 \\
\hline Radius Matching, caliper(0.5) & 40 & 175 & -1.55 & 0.833 & -1.86 & -3.2 & 0.1 \\
\hline \multicolumn{8}{|l|}{ Probability of wanting more credit in \% } \\
\hline Kernel Matching (epanechnikov) & 123 & 854 & $-7.2 \%$ & 0.039 & -1.83 & $-15 \%$ & $0.5 \%$ \\
\hline Kernel Matching (Gaussian) & 123 & 854 & $-3.2 \%$ & 0.069 & -0.46 & $-17 \%$ & $10.5 \%$ \\
\hline Radius Matching & 123 & 854 & $-9 \%$ & 0.039 & -2.29 & $-16.6 \%$ & $-1.3 \%$ \\
\hline Radius Matching, caliper(0.01) & 120 & 853 & $-4.8 \%$ & 0.050 & -0.96 & $-14.6 \%$ & $5 \%$ \\
\hline Radius Matching, caliper(0.5) & 120 & 853 & $-7.2 \%$ & 0.048 & -1.50 & $-16.6 \%$ & $2.2 \%$ \\
\hline
\end{tabular}

Source: Authors using the 2005 Nicaragua EMNV. ${ }^{++}$The program, previous to perform the sensibility analysis, calculates a baseline estimate. In this case using kernel matching and only observation on the common support the baseline estimate is $8.5 \%$. 